\title{
The Question of the Self-Refuting Character of Protagorean Relativism in the Theaetetus
}

\section{Matt Waldschlagel \\ University of Kansas}

The Theaetetus is the first sustained philosophical inquiry into knowledge. The dialogue is presented through the conversations of five characters-Euclides, Terpsion, Socrates, Theodorus, and Theaetetus - the last three of which carry the burden of the dialogue. Early in the dialogue, Socrates, Theodorus, and Theaetetus consider the question "What is knowledge?" and spend the rest of the dialogue entertaining three theories of knowledge. The first theory is that knowledge is perception, the second that knowledge is true judgment, and the third that knowledge is true judgment with an account. Through the method of question and answer, Socrates shows that each account fails to properly capture what knowledge is in some way or another. The dialogue concludes without a positive answer to the question, though the three main interlocutors agree to meet the following day to continue their conversation.

This paper will investigate the first of the three theories of knowledge offered by Theaetetus, namely, that knowledge is perception. In particular, this paper will address the claim that the Protagorean relativism employed as a defense of the first theory is self-refuting. Many fine Plato scholars and other philosophers argue that Protagorean relativism is self-refuting, among them Myles Burnyeat,' Ronald M. Polansky, ${ }^{2}$ and John Passmore. ${ }^{3}$ However, in her article "Protagoras and Inconsistency," Sarah Waterlow offers a rival interpretation of Protagoras' relativism under which relativism doesn't so much refute itself as show itself to be, in her words, a "dialectical nothing." I aim to make clear in this paper Waterlow's interpretation of Protagoras' relativism and her criticism of the Burnyeat/Polansky/Passmore position [hereafter BPP]. I will also defend Waterlow's interpretion against the BPP position. First, though, a significant amount of background on the dialogue is required. 
The substantive dialogue begins when Socrates runs into Theodorus, an old man and respected mathematician from Cyrene. Theodorus tells Socrates about Theaetetus, the old mathematician's brightest and most "amazingly gifted"student (144a). Socrates decides to stay and "examine" the young Theaetetus (145b). Theaetetus reports to Socrates that he is learning geometry, astronomy, music, and arithmetic from Theodorus. In response, Socrates states that such learning should make him become wisethat is, an expert-about that which he studies. ${ }^{5}$ Socrates then makes known a worry that he thinks Theaetetus and Theodorus can help him investigate. The worry is an epistemic one: Socrates says that he "can't get a proper grasp of what on earth knowledge really is" (146a). Theaetetus' brief description of his own course of study and Socrates' mention of the expertise it is thought that Theaetetus should acquire as his learning progresses frames the context for Socrates' worry. Burnyeat identifies the bearing the worry has on the very idea of expertise explaining that "[e]xpertise is specialized knowledge (knowledge which most people do not have), hence it is problematic if knowledge itself is problematic." So, the worry is not 'merely academic.' At stake in the answer to the question is the justification for our belief in expertise and the order of the social world it makes possible in the form of the teacherstudent relationship, the master-apprentice association, etc.

Theaetetus' first answer was simply a list of some of the branches of theoretical and practical knowledge (146d). In response, Socrates reminds Theaetetus that he was "not asked to say what one may have knowledge of, or how many branches of knowledge there are... [but rather] what knowledge itself is" (146e). After this clarification is offered and after Socrates explains to Theaetetus that his (Socrates') role as interlocutor is likened to that of a midwife, helping the youth give birth to ideas as women give birth to newborns, Theaetetus produces his second answer, that "knowledge is simply perception" (151e). Given that the justification of expertise is riding on the answer to the question, it may be surprising that Theaetetus throws down such an unamenable answer. In fact, Burnyeat somewhat rhetorically asks, "should we ... take . . . 
expertise as something which an adequate account of knowledge should cater for? That, however, might lead us to think that Theaetetus' first properly formulated definition, 'Knowledge is perception', is mistaken from the start." Burnyeat is, I think, correct in this assessment. ${ }^{8}$

As the conversation between Theaetetus and Socrates progresses, two other theses are added to the claim that 'knowledge is perception' to support it, namely, Protagoras' doctrine that man is the measure of all things and Heraclitus' extreme flux theory. Protagoras' doctrine, as Socrates understands it, is that "as each thing appears to me, so it is for me, and as it appears to you, so it is for you" (152a). In fact, perception "is always of what is, and unerring - as befits knowledge" (152c). Burnyeat interprets this to mean that "however things appear to someone, things are for this person just the way they appear, and if they appear different to someone else, then for that person they really and truly are different." The extreme flux theory of Heraclitus is that everything is constantly changing, paradoxically summed up in the dictum that 'you cannot step into the same river twice.' The relationship between these three theses and Plato's posture toward them merit attention.

As midwife, Socrates urges Theaetetus to give birth to his idea by thinking about what must be the case if it is a true account: if perception is knowledge and if we perceive whatever appears to us through our senses, then it must be the case that each individual "man is the measure of all things: of the things which are, that they are, and of the things which are not, that they are not" (152a). Call this the Measure Doctrine. According to Theaetetus, perception alone "provides knowledge and certainty, and from Protagoras' Measure Doctrine we have a guarantee that every perceptual appearance will be the unerring apprehension of how things are for the perceiver." 10 Consider the case of two perceivers out and about on a windy day. To one of them, the wind appears cold; to the other, the wind appears warm. According to Protagoras, if the wind is cold for one perceiver and not for another, then it cannot be the case that one perceiver is right and the other wrong. It cannot even be said that both are wrong. There simply "is no such thing as the temperature of the wind by which to correct, or confirm, some- 
one"ll who says anything about the temperature of the wind. No independent fact about the temperature of the wind exists about which anyone could be mistaken. Each perceiver, then, is necessarily and unmistakably correct about how things perceived are for him.

The best metaphysical support for the epistemological queerness of the Measure Doctrine is that what is perceived is constantly changing. There is no such thing as the temperature of wind as such because there are no objects or properties of objects that endure through time. This is Heraclitus' Extreme Flux account. According to this account, "there is nothing but motion" (156a), where the specific sense-experiences of an agent are "constituted in and by the interplay of various motions including those which are his sense-organs."12 Burnyeat claims that the Heraclitean story "teaches us that there are no things, only processes-the world is a vast array of motions." 13 So, knowledge is perception because each man is his own measure of the world, where the world is itself nothing but a complex of patterns of motion. Ironically, it is Socrates' expertise in conducting the method of question and answer that exhibits the many flaws in Theaetetus' first account of knowledge. ${ }^{14}$

Consider, for a moment, the relativism of the Measure Doctrine. In showing the link between the Measure Doctrine and the Extreme Flux account, Burnyeat helps to bring to light the relativism required by the 'knowledge is perception' story. Burnyeat explains that "[o]bjects cannot have a continuing identity through time if every feature they manifest is relativized to a single perceiver and to the time of their perception, and every feature must be so relativized if perceptual awareness is incorrigible: stability through time, no less than objectivity between different observers, would constitute an independent fact of the matter by reference to which one perception could be counted right, another wrong."15 Socrates characterizes this relativism in representing the Protagorean position when he says that "my perception is true for me-because it is always a perception of that being which is peculiarly mine" (160c). After laying out the nuances of the "knowledge is perception" theory, Socrates tries his hand at criticizing it, suggesting that such a relativistic theory makes unintelligible the very idea of ex- 
pertise that a good theory of knowledge, it seems, should defend. In fact, the expertise of Protagoras himself, the author of the Measure Doctrine, is thrown into question. Socrates asks Theodorus why anyone should pay the supposedly wise Protagoras any sum of money to listen to his purported wisdom when we "are ourselves each the measure of his own wisdom?" (161e).

The answer to this question-and Socrates' own generous defense of Protagoras at $165 \mathrm{e}-168 \mathrm{c}$-need not concern us here. Instead, notice the way that Plato expands the scope of the level of reflection on the status of things relativized. Up to this point in the dialogue, "the strategy of relativization has been applied only to the sensory predicates involved in perception (152c), although 'good' and 'bad' were slipped in at $157 \mathrm{~d} . "{ }^{\prime \prime 6}$ However, beginning at $161 \mathrm{~d}$, Plato takes the Measure Doctrine to apply not only to all perceptions, but to all judgments as well. ${ }^{17}$ Take the Protagorean formula ' $x$ appears $F$ to $a$,' which, in our earlier example, became 'the wind appears cold to me.' Beginning at $161 \mathrm{~d}$ in the dialogue, instead of a "sensible object appearing to a perceiver, . . .x may be, for example, a law or practice (167c) or someone's opinion (171a), $a$ may be a whole city as well as any individual (167c, 172a), and the predicate term $F$ may be 'just' (167c, 172a), 'false' (170d, 171a), 'persuasive' (178e)." ${ }^{18}$ Between 169d-171d, Protagoras' Measure Doctrine stands in the place of $x$. With this move, Plato sets Socrates up to consider the status of the Measure Doctrine within the epistemic parameters of what the Doctrine itself permits.

\section{II}

This brings me to the particular concern that I now want to consider: the flaw that Burnyeat, Polansky, and Passmore suppose Plato to have discovered, exploited, and criticized. The flaw is that of the alleged self-refuting character of the relativism of the Protagorean account, when the account is treated within the epistemic parameters just mentioned. At 171a, Socrates notes that the Measure Doctrine "has this most exquisite feature: Protagoras admits... that the contrary opinion about his own opinion (namely, that it is false) must be true, seeing he agrees that all men judge what is." Yet, if this is the case, Socrates shrewdly demonstrates, then "in 
conceding the truth of the opinion of those who think him wrong, he [Protagoras] is really admitting the falsity of his own opinion" (171b). Hence, it appears that Socrates has shown Protagoreanism to be self-refuting. Socrates' last challenging question at 171c, left unanswered by the weary, befuddled Theodorus, should, it seems, have driven the final nail into Protagoras' coffin: "since it is disputed by everyone, the Truth of Protagoras is not true for anyone at all, not even for himself?" The obvious answer is a resounding "yes." All this seems to indisputably support the BPP position.

Burnyeat is convinced that it does. The following is his reconstruction of the argument:

[L]et us consider... the widespread belief that people are sometimes ignorant and wrong, that false judgment does occur. If people are right to think that there is false judgment, there is. But equally, if they are wrong in this belief, there is false judgment (for here is an instance of it). But Protagoras must say-must he not?-either that they are right or that they are wrong: unless he is willing to go so far as to deny that people do hold this view about each other's ignorance and expertise. To deny that, Theodorus agrees, would be quite implausible (170c). So Protagoras is caught in a dilemma. Whichever answer he gives has the consequence that false judgment occurs, which the Measure Doctrine must deny. ${ }^{19}$

Essentially, Burnyeat claims that Protagorean "relativism is selfrefuting, and for reasons that go deep into the nature of assertion and belief."20

A somewhat similar assessment is offered by Passmore. ${ }^{21}$ Passmore's reconstruction of Plato's argument at 171a-171d is as follows:

[I]f Protagoras is right in thinking that what anyone takes to be true is true, it will follow that his opponents are right in denying that that which anyone takes to be true is true, since this is how matters appear to them. So if Protagoras is correct, it will follow both that man is the measure of all things (since this is how it appears to Protagoras) and that man is not the measure of all things (since this is how it appears to his opponents). Hence his theory is in a precise sense self-contradictory. ${ }^{22}$ 
Finally, Polansky succinctly sums up the difficulty with Protagoras in just two sentences:

For the person denying that he is the measure, it is true to that person that he is no measure. While in a sense this accords with the doctrine, because it makes truth relative, it also subverts the doctrine, for inasmuch as it is true to that person that he is not a measure, the supposition that every person is a measure becomes false. ${ }^{23}$

The interpretations of Burnyeat, Passmore, and Polansky clearly constitute a unified position on the question of the self-refuting ${ }^{24}$ character of Protagoreanism.

\section{III}

Enter Sarah Waterlow, the voice of dissent. Waterlow acknowledges that were he "[j]udged by standard logical principles, Protagoras would certainly appear to be contradicting himself by ... agreeing to his opponents' assertion that the doctrine is false and that not every sentient being 'is a measure." ${ }^{25}$ As we will see, however, Protagoras cannot be held to or judged by standard logical principles, such as the law of non-contradiction. On account of this, Waterlow is critical of the reading of the relativism of the Theaetetus supported by the BPP position.

Assume for the moment that Plato really is trying to show Protagorean relativism to be self-refuting on the grounds that it is inconsistent. Plato, then, according to Waterlow, will prove the position untenable because an inconsistent position is

necessarily false ... [However,] if he aims to show that it is necessarily false, he flagrantly begs the question against Protagoras. For the issue is, precisely, whether opinions can be false. To argue on the assumption that a position of a certain nature (viz. an inconsistent position) is necessarily false, is already to have assumed that such a position can be false, which is exactly what Protagoras denies concerning all positions that are actually held as opinions ... It would be useless, then to show that Protagoras holds an inconsistent set of beliefs. By his lights, whatever is believed is true. It follows that even what is inconsis- 
tently believed is true, even when the inconsistency occurs in beliefs held by the same subject, e.g. Protagoras himself. ${ }^{26}$

The charge of self-refutation, then, is no reason to reject as false a theory that is committed to its own negation. So, if Plato's argument were that the Protagorean position is false on the grounds that it is inconsistent, the argument would be fallacious because it assumes the very thing it attempts to prove. The principle of charity suggests that Plato doesn't really endorse a fallacious argument, so we should consider Waterlow's alternative reading. And since the BPP position is that Plato argued that Protagorean relativism is self-refuting, the BPP position is inadequate.

A second argument against the BPP position concerns the impossibility of the application of the law of non-contradiction to Protagoras' relativism. According to a Waterlowvian analysis of Protagorean relativism, what is inconsistently believed is true, even when the inconsistency occurs in beliefs held by (what ostensibly looks like) the same subject. Yet, surely, if there were ever an example where an inconsistency led to a falsity, this would appear to be it. However, Waterlow states that

a contradiction can only occur when it is the same subject that holds both contradictory beliefs. But the Theaetetan Protagoras is a Heraclitean. He professes to hold that a subject is never the same from one instant to another. He can argue, therefore, that even if it seems that he, Protagoras, is guilty of inconsistency, the expression 'he, Protagoras' denotes a fiction .... We ought to regard each of what appears to be a contradiction as a separate belief belonging to a different subject. Before one has finished thinking ' $p$ and q' (where ' $q$ ' entails 'not-p'), the 'one' has been replaced. ${ }^{27}$

So, the charge of inconsistency is never a threat to Protagorean relativism, because inconsistency never occurs.

III.A

Let us now consider the Waterlowvian interpretation of Protagorean relativism. Waterlow makes what she takes to be a crucial distinction between agreeing with an interlocutor and shar- 
ing with them their opinion, a distinction the recognition of which, she claims, should change how we read the relativism of the Theaetetus. In explaining her reading of the agreeing/sharing distinction and its significance in reconsidering the BPP position on Protagorean relativism, Waterlow states that it should "be noted that Plato does not show Protagoras actually asserting that his doctrine is false, or as asserting its contradictory. He presents him as simply agreeing to the opponents' assertions." ${ }^{28}$ Waterlow suggests that we should not assume that agreeing with an opinion entails that one likewise holds the opinion in question. If we do assume that agreeing entails sharing, and the opinion so agreed upon is inconsistent with another opinion already held, then the individual that agrees has contradicted herself. But this, Waterlow argues, couldn't possibly represent what's going on with Protagoras, for being convicted of an inconsistency would be of no consequence for Protagoras, as being so convicted is not a prima facie indication of falsity. Protagoras, then, does not make the agreeing/ sharing distinction so as to avoid contradiction. Nonetheless, Waterlow claims that Protagorean relativism trades on a distinction between agreeing and sharing in the Theaetetus.

Consider the following conditional: only if A's agreement with $B$ 's assertion necessarily entails that A also asserts what B holds would it then "follow from Protagoras' agreement with his opponents that he too shares their view and so contradicts his own thesis. ${ }^{29}$ However, by linking the Measure Doctrine to the Extreme Flux account, and granting the existence of at least two different observers in a world of extreme flux to whom the Measure Doctrine applies, Protagoras' relativism nullifies any such necessary entailment. Although he says that all beliefs are true, Protagoras "does not himself subscribe to all beliefs. His admission that another's belief is true is the admission that there is, relatively to that other, a reality that makes the latter's belief a true one." ${ }^{.30}$ This admission clearly follows from the Measure Doctrine, according to which "each subject has his own set of appearances and objects making them true."31

The existence of my relative reality, then, does not entail the existence of a qualitatively identical relative reality for you. Although Protagoras must agree with his opponent's opposing view 
by holding it to be true, "it does not follow that he shares in that view. But unless he shares in it, he does not contradict himself, for he does not hold any view that conflicts with his doctrine." ${ }^{.32}$ And yet, even if Protagoras were to contradict himself, such a contradiction would not be an indication of the falsity of opinion so expressed. The agreeing/sharing distinction simply follows as a necessary consequence of the Measure Doctrine and the Extreme Flux account, and thus is not introduced as a stopgap measure to avoid the "threat" of self-contradiction, which could never defeat Protagorean relativism in the first place.

\section{B}

The specific character of Waterlow's interpretation of Protagoras' relativism deserves an explanation. Waterlow warns that the kind of relativism in question cannot be a relativism of truth, as the

question of truth can only arise once a conceptual distinction is made (not that Protagoras considers how, if his theory is true, we could ever have come to make it) between what are really only aspects of the same thing, the appearance and its object. All appearances are true precisely because the object cannot fail to exist when the appearance exists. ${ }^{33}$

According to Waterlow, Protagorean relativism is a relativism of fact, for "[w] hat is relative to the believer is the reality that makes the belief true. It is what is measured that exists only for, or relatively to, the man that is its measure." 34 Consider again the example of two individuals perceiving the temperature of the wind. One of the perceivers holds the view that the wind is hot; the other perceiver holds the view that the wind is cold. According to the Waterlowvian analysis, they each hold the views that they do because they each experience a different reality. This interpretation of the character of Protagoras' relativism is based on the theory of perception "according to which there is no ontological distinction between an appearance and the quality of which it is an appearance." 35 In other words, in Protagoras' theory of perception, there is no objective reality behind the appearances against which differ- 
ent observers could intersubjectively check their observations. Precisely because there is no objective reality behind the appearances, to hold a view is to have a reality. Yet when the agent who perceives the cold wind agrees with the agent who perceives the hot wind that the wind is hot, she is not sharing with that agent the same experience of the same reality-is not, that is, sharing with the other perceiver an inner belief-state of qualitatively identical content. Rather, possessed of intellectual virtue, the agent who agrees (though does not necessarily share) is doing what is required by the Measure Doctrine.

Waterlow continues to argue that

while both appearance and object depend for their existence on the subject, it is not the case that the relation "between" them (namely, their ultimate identity, which ensures that the appearance can never not be of an object) is itself something further that also depends for its existence on the subject. The being true of the appearance simply follows from the appearance's existing at all. Thus Protagoras can, and does, say that a belief is true (simpliciter), not true-for-a-subject. ${ }^{36}$

This, however, changes how we think of the scope of Protagoras' Measure Doctrine. Waterlow argues that Protagoras must ultimately admit that "this doctrine of his concerning appearances and truth is itself only an appearance to him, Protagoras, and hence is made true by a fact that exists relatively to himself." ${ }^{37}$ The truthmaker (viz. reality) that makes his own theory true exists only relatively to Protagoras himself. Still, in terms consistent with his theory, Protagoras can "maintain that since relative reality exists (so that his appearance has an object), the ... [theory-as-appearing-to-him] is true (simpliciter)." ${ }^{\text {38 }}$

\section{Conclusion}

If Waterlow's interpretation is correct, where does it leave us? According to the BPP position, Protagorean relativism is a selfrefuting position that for reasons of logic must be rejected. But, as we saw, the interpretation on which the BPP position rests is inadequate. What is Plato's position on Protagorean relativism, if, in- 
deed, it isn't self-refuting? Waterlow claims that Plato really sees the Protagorean position as a "dialectical nothing." tor cannot get any purchase on Protagoras in an argument, given that there is no way to ever negotiate with him. Protagoras offers no resistance to an interlocutor in a philosophical conversation; in fact, Protagoras never rejects any proposition that any opponent ever floats by him. Protagoras cannot even inject any doubt in his own opinions, as the very possibility of doubt would imply that an appearance might be false. Protagorean relativism, then, is a conversational non-starter. Nothing any interlocutor can say can logically compel Protagoras to change, protect, rethink or even reaffirm his own opinions. The act of elenchus with Protagoras is simply impossible; one never "gets anywhere" in the conversation. There simply is no offspring for Socrates as midwife to deliver, not even a wind egg.

Waterlow's interpretation is internally coherent and textually sensitive. What is most surprising about the BPP position is that two of the three contributors to the position wrote their commentaries on the Theaetetus well after the publication, in 1977, of Waterlow's article. Neither Burnyeat's commentary, published in 1990 , nor Polansky's commentary, published in 1992, deal with the complexities raised by Waterlow's article. Burnyeat's article cites Waterlow's article only once in a footnote, urging the reader to compare his own 1976 article with Waterlow's account. Polansky does not use the article in any capacity in the commentary itself, let alone even cite the article in his bibliography. Paying attention to her article would have made Polansky's and Burnyeat's works more engaging, more authoritative, and more philosophically astute.

\section{Notes}

' See Myles Burnyeat, The Theaetetus of Plato, (Indianapolis: Hackett, 1990), 30.

2 See Ronald M. Polansky, Philosophy and Knowledge: A Commentary on Plato's Theaetetus, (Lewisburg: Bucknell University Press, 1992), 129-131.

${ }^{3}$ See John Passmore, Philosophical Reasoning, (New York: Charles Scribners' Sons, 1961), 67. 
"Sarah Waterlow, "Protagoras and Inconsistency" Archiv fur Geschichte der Philosophie 59 (1977), 36.

${ }^{5}$ The editor of the Theaetetus suggests that readers substitute in their minds the words "expert" and expertise" for the words "wise" and "wisdom." In this paper, I follow that convention, though in print.

${ }^{6}$ Burnyeat, 3.

${ }^{7}$ Burnyeat, 4 .

${ }^{8}$ That the conclusion of the dialogue is aporetic might suggest to some readers that since no satisfactory answer to Socrates' epistemic worry is given, the idea of expertise is itself thrown into doubt. This is not the case as aporia, I think, plays a positive role. Unfortunately, I do not have the space to develop this idea further here. For the positive role of aporia, see Rosemary Desjardins, The Rational Enterprise: Logos in Plato's Theaetetus (Albany: SUNY Press, 1990), 4-8.

${ }^{9}$ Burnyeat, 7-8.

${ }^{10}$ Burnyeat, 15.

"Burnyeat, 15.

12 David J. Melling, Understanding Plato, (Oxford: Oxford University Press, 1987), 128.

${ }^{13}$ Burnyeat, 16.

${ }^{14}$ Ironic, that is, because at $150 \mathrm{c}$, Socrates states that he is "barren of wisdom," indicating that he is not an expert at anything, even, it seems, the method of question and answer.

is Burnyeat, 17. Emphasis mine.

${ }^{16}$ Burnyeat, 20.

${ }^{17}$ See Francis M. Cornford, Plato's Theory of Knowledge:The Theaetetus and the Sophist, (Mineola: Dover Publications, Inc., 1957), 76.

${ }^{18}$ Burnyeat, 21.

${ }^{19}$ Burnyeat, 28-29.

${ }^{20}$ Burnyeat, 30.

${ }^{21}$ However, it appears as if Passmore, in attempting to refute Protagoras, leaves out the relative truth predicates (i.e., "true to you" or "true to me"), and thus mischaracterizes Protagoras' view.

22 Passmore, 67.

${ }^{23}$ Polansky, 131.

${ }^{24}$ This is Burnyeat's phrase. Passmore and Polansky use the term "self-contradictory" to describe Protagoreanism. Despite the differences between these terms, I believe that enough similarity exists to warrant making Passmore and Polansky echo Burnyeat's phrase.

${ }^{25}$ Waterlow, 29.

${ }^{26}$ Waterlow, $23 \& 25$. 
${ }^{27}$ Waterlow, 26-27.

${ }^{28}$ Waterlow, 29.

${ }^{29}$ Waterlow, 30.

${ }^{30}$ Waterlow, 30.

${ }^{31}$ Waterlow, 32.

${ }^{32}$ Waterlow, 30.

${ }^{33}$ Waterlow, 32.

${ }^{34}$ Waterlow, 32.

${ }^{35}$ Waterlow, 32.

${ }^{36}$ Waterlow, 32.

${ }^{37}$ Waterlow, 33.

${ }^{38}$ Waterlow, 33.

${ }^{39}$ Waterlow, 36. 